\title{
Controlling the Photo-Degradation Rate Constant of PS Containing Nickel(II) Complex
}

\author{
Zainab Hussain ${ }^{1}$, Raghda Alsayed ${ }^{2}$, Atheel Alwash ${ }^{2}$, Ahmed Ahmed ${ }^{3}$, Riyadh Noaman ${ }^{4}$, \\ Ali H. Jawad ${ }^{5}$ and Emad Yousif ${ }^{2 *}$ \\ ${ }^{1}$ Department of Chemistry, College of Science, Misan University, Misan-Iraq. \\ ${ }^{2}$ Department of Chemistry, College of Science, Al-Nahrain University, Baghdad-Iraq. \\ ${ }^{3}$ Polymer Research Unit, College of Science, Al-Mustansiryah University, Baghdad-Iraq. \\ ${ }^{4}$ Chemical and Petrochemical Research Center, Corporation of Research and Industrial Development, \\ Ministry of Industry and Minerals, Baghdad-Iraq. \\ ${ }^{5}$ Faculty of Applied Sciences, Universiti Teknologi MARA, Shah Alam, Selangor, Malaysia. \\ * Corresponding Author: emad_yousif@ hotmail.com
}

\begin{abstract}
The complex of Ni(II) metal with 4-amino-5-(pyridyl)-4H-1,2,4-triazole-3-thiol was used as a polystyrene (PS) films photostabilizer. The PS films comprising concentrating of complex $0.5 \%$ wlw were outputted by casting method from chloroform solvent. The photostabilization activities of PS films compounds with dissimilar thickness were identified by computing the photodegradation rate constant $\left(k_{d}\right)$ for blank and modified polystyrene. From the practical consequences obtained, a mechanism was proposed count on the installation of the complex. The PS films were irradiated utilizing a $365 \mathrm{~nm}$ wavelength light source with intensity $6.02 \quad 10^{-9}$ Ein $\mathrm{dm}^{-3} \mathrm{~s}^{-1}$ at room temperature. [DOI: 10.22401/ANJS.22.3.02]
\end{abstract}

Keywords: Ni(II) complex, PS, Photochemistry, photodegradation.

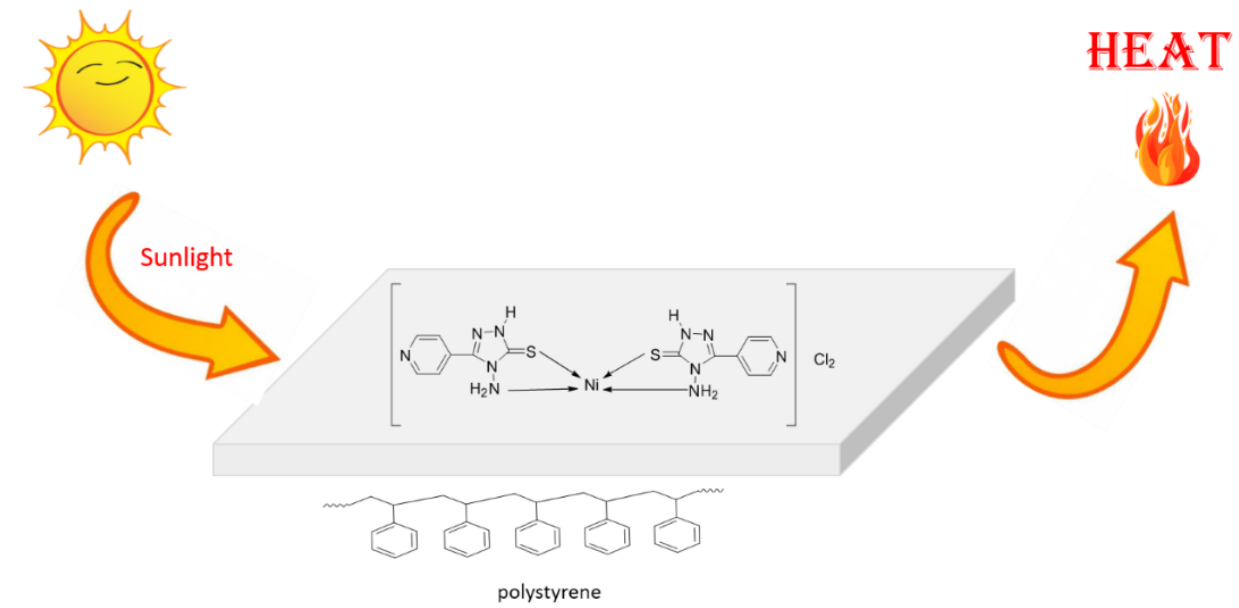

\section{Introduction}

A wide-ranging assortment of artificial and naturally high polymers, when absorbing UV radiance, they suffer photo-oxidative degradation and the consequences of that are shattering of the chains of the polymer, generating radicals and curtail the molecular mass. These lead to, after an unpredictable time, deteriorate of mechanical properties and leading to make it inutile materials [1,2]. Polystyrene (PS) is one of the most widespread type of saleable polymers in the world, this because of its fantastic physical properties, low creation costs and the gigantic assortment of its applications, where it is utilized in packaging, laboratory ware, and electronics [3-4]. Photodegradation of polymers that come about because of the influence of light in the existence of air relies on the polymer nature, the wavelength of the UV light, the intensity of radiance, and other parameters such as temperature and the existence of metallic traces [5-6]. UV light energy when absorbed triggering to the separation of bonds (for the most part $\mathrm{C}-\mathrm{C}$ and $\mathrm{C}-\mathrm{H}$ ) in the molecules of one or more of the constituents of a polymeric material this occurred in a homolytic process producer free radicals that represent the initial photochemical products. This happening with or without the involvement of oxygen, thereafter can lead to one or more of the 
following chemical changes: scission of the chain, crosslinking, dissociate of small molecules (water, carbon monoxide, carbon dioxide, hydro chloric acid, etc.), creation of double bonds in the basis chain, depolymerization, and photohydrolysis [7-8]. Likewise, the loss of physical properties of plastics, such as color change (turn yellow) [910] break, shatter or even melt and other troubles correlated with UV exposure [11-13]. All synthetic polymers necessitate stabilization against opposing ecological special influence. It is important to discover a way decrease or inhibit harm induced by ecological components such as light, heat \& oxygen [1415]. There are numerous of light stabilizers which the nature of its work is highly reliant the absorption of UV light, radical scavengers, excited state quenchers, light screeners, and peroxide decomposers [16-20]. As of late, we have revealed the utilization of several additives to rise photostabilizing effectiveness and photochemical steadiness of polymeric substances [21-22] as portion of our concern in the preparation of polymeric substances with intriguing applications [23-24], one of these additives is metal chelates [25-26]. In this paper we report the fruitful utilize of $\mathrm{Ni}$ (II) with 4-amino-5-(pyridiyle)-4H-1,2,4triazol-3-thiol for photostabilization of polystyrene and was studied in different thickness of PS films (50, 60, 70, 80 and 90 $\mu \mathrm{m})$.

\section{Experimental Technique Film preparation}

Polystyrene (PS) has been dissolved with complex of $\mathrm{Ni}(\mathrm{II})$ with 4-amino-5-(pyridyl)4H-1,2,4-triazole-3-thiol [27] in chloroform as a solvent to constitute Polystyrene films in different thicknesses, A solution of polystyrene $(5 \%, 6 \%, 7 \%, 8 \%$ and $9 \%$ weight/volume) in chloroform was utilized to make polymer films which contain $0.5 \%$ wlw from $\mathrm{Ni}$ (II) complex. Their thicknesses were identified by a micrometer type (2610 A, Germany). These films were made by evaporating at room temperature for $24 \mathrm{hrs}$ to expel the remains of the solvent (chloroform). [28,29]. Fig.(1) shows the structure of complex.

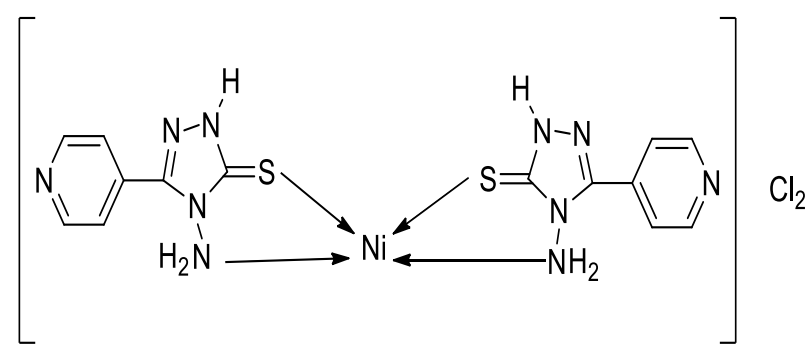

Fig. (1): Structure of $\mathrm{Ni}(\mathrm{L})_{2}$ Complex.

\section{Irradiation Part \\ Accelerated testing technique}

UV lamp was utilized to irradiation the films where this lamp gives a spectrum in the range (250-380) $\mathrm{nm}$ and beam intensity is 6.2 $\times 10^{-9}$ Ein $\mathrm{dm}^{-3} \mathrm{~s}^{-1}$. The films were placed parallel to each other. Where the beam incident vertically on these samples and what's more the extent between the films and the source of radiation equal to $(10) \mathrm{cm}$. The samples that irradiated were replaced in close periods to assure that the intensity of light incident on all samples is equal [30].

\section{Photo-degradation Measuring Methods}

The absorption spectrum was measured in the extent (200-400) $\mathrm{nm}$. The variations in the Uv-visible spectrum at extreme absorption and $\left(\lambda_{\max }\right)$ was measured for each compound at diverse radiation times utilizing a UV spectrophotometer kind Shimadzu UV-VIS. 160 [31]. The immeasurable radiation time was viewed as \& the immeasurable absorption $\left(\mathrm{A}_{\infty}\right)$ was presumed to be after the immeasurable radiation time. For decide the photo-degradation rate constant for photostabilizer $k_{d}$, the $1^{\text {st }}$ order equation was used:

$\ln (\mathrm{a}-\mathrm{x})=\ln \mathrm{a}-\mathrm{k}_{\mathrm{d}} \mathrm{t}$

$\mathrm{a}$ is the concentricity of photostabilizer before radiation, $\mathrm{x}$ is the variation in the concentricity of photostabilizer after $(t)$ time of radiation.

If $A_{o}$ is the absorption of films that comprise of the preservative before radiation and $A_{t}$ is the absorption of this films after $t$ time of radiation, consequently:

$a=A_{\infty}-A_{o}, x=A_{t}-A_{o}$

$\mathrm{a}-\mathrm{X}=\mathrm{A}_{\infty}-\mathrm{A}_{0}-\mathrm{A}_{\mathrm{t}}+\mathrm{A}_{\mathrm{o}}=\mathrm{A}_{\infty}-\mathrm{A}$ 
Exchange a and $\mathrm{a}-\mathrm{x}$ from equation 3 in 2 gives:

$\ln \left(\mathrm{A}_{\infty}-\mathrm{A}_{\mathrm{t}}\right)=\ln \left(\mathrm{A}_{\infty}-\mathrm{A}_{\mathrm{o}}\right)-\mathrm{k}_{\mathrm{d}} \mathrm{t}$

Hence, when drawing $\ln \left(\mathrm{A}_{\infty}-\mathrm{A}_{\mathrm{t}}\right)$ vs. irradiation time $(\mathrm{t})$, we will get the straight line its slope represent $\left(k_{d}\right)$, which shows that the process of photodecomposition added substances is the first order.

\section{Results \& Discussion}

$\mathrm{Ni}(\mathrm{II})$ with 4-amino-5-(pyridyl)-4H-1,2,4triazole-3-thiol complex was utilized as added substances for photo-stabilization of PS films in various thicknesses. So as to study the photo-chemical action of these added substances for the photostabilization of Polystyrene films. Generally, the photooxidation amount decrease with growing film thickness [32]. Since the oxygen dissemination rate for a given amount of polymer is relative to the superficial area and reduction with growing film thickness. Hence in the current paper, the photo-degradation of PS films was examined in various thickness $(50,60,70,80$ and $90 \mu \mathrm{m})$ with and without fixed
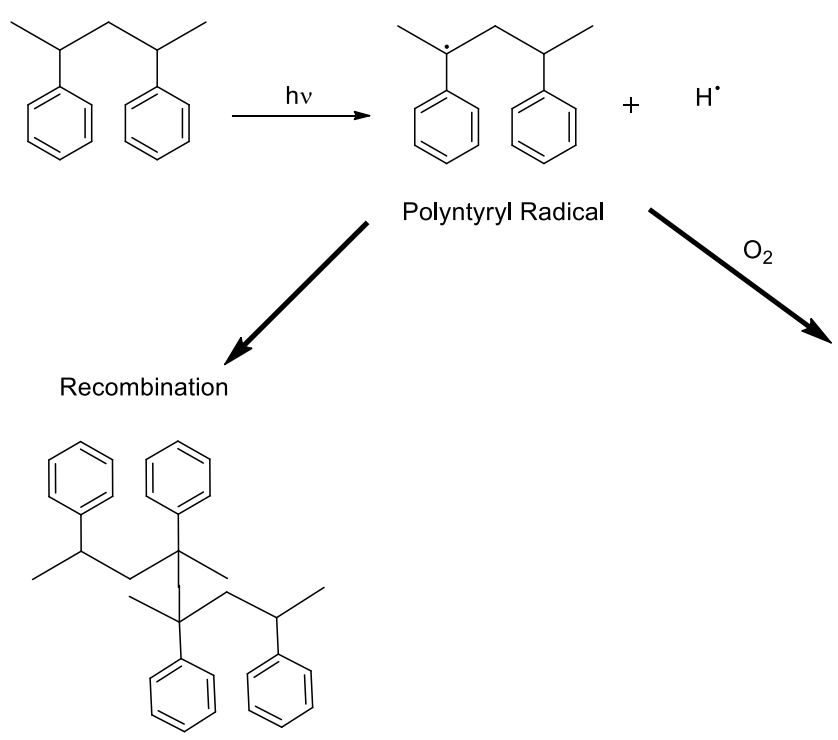

concentration $(0.5 \%)$ of the additives indicate that the rate of photooxidation carbonyl at steady radiation time is steadily declined with increasing film thickness for all added substances utilized, together with the PS control . Here, in this kind of mechanism of photo-oxidation, the essential parameter influencing on the rate of degradation is film thickness. So, the Ni complexes deemed as photostabilizer for PS. Similar consequences are accessed for the influence of thickness on the rate of photodegradation and photostabilization of vinyl polymers utilizing iron(III), manganese(III), Nickel(II) and copper(II) acetylacetonate complexes as additives in polystyrene films [33]. The mechanism of photodegradation of PS in existence of $\mathrm{O}_{2}$ is displays in Fig.(2).

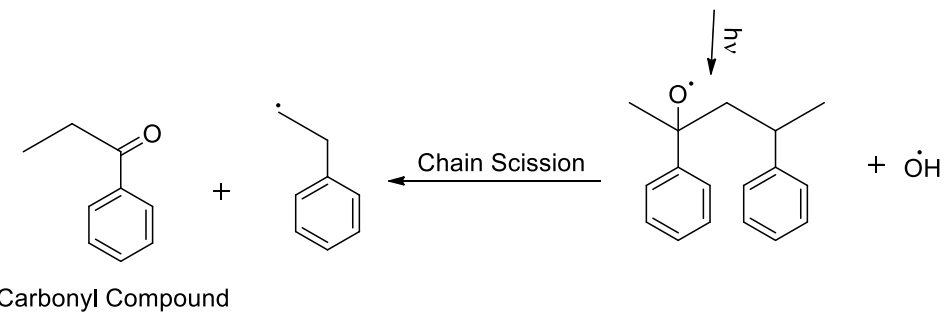

Fig. (2): General mechanism of photodegradation of PS. 
During the photo-oxidation of the polymer, the carbonyl groups will be formed and the polymeric films absorption will be extended to taller wavelengths $[34,43]$. These gatherings absorb radiation as soon as they exposed to light have wavelength in the range 200-700 $\mathrm{nm}$ and stimulate to the singlet and triplet excited states which improves many succeeding photo-oxidation reactions [35]. Hence, photo-degradation rate constant $k_{d}$ values were calculated Depending on the UV spectrum variations of PS films with different thickness (50-90) $\mu \mathrm{m}$ comprising $0.5 \%$ from added substances. As we have already shown, when drawing $\ln \left(A_{\infty}-A_{t}\right)$ vs. irradiation time $(\mathrm{t})$, we will get the straight line its slope represent $\left(k_{d}\right)$, which shows that the process of photo-decomposition of the added substances is the first order. Figures (3 - 8) illustrations the diversity of $\ln \left(\mathrm{A}_{\mathrm{t}}-\mathrm{A}_{\alpha}\right)$ with the radiation time of the modified polystyrene films at different thicknesses at $\lambda=365 \mathrm{~nm}$. The $k_{d}$ values were counted by the similar way. These values were displays in Table (1). Any thickness of modified polymer films possesses a little $k_{d}$ value, which denote that the improved polymers in this thickness are extra steady toward Ultra-Violet light.

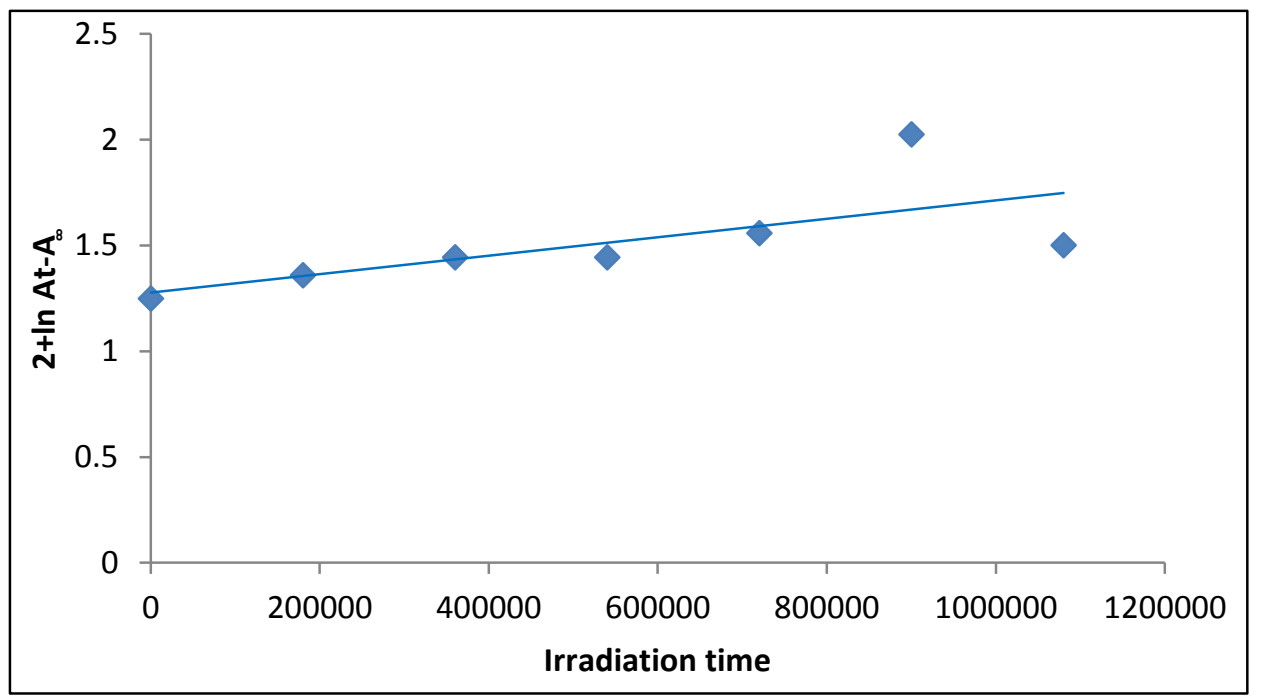

Fig.(3): plot of $\ln (A t-A \infty)$ vs radiation time of PS blank film in thickness $50 \mu \mathrm{m}$ at $\lambda=365 \mathrm{~nm}$.

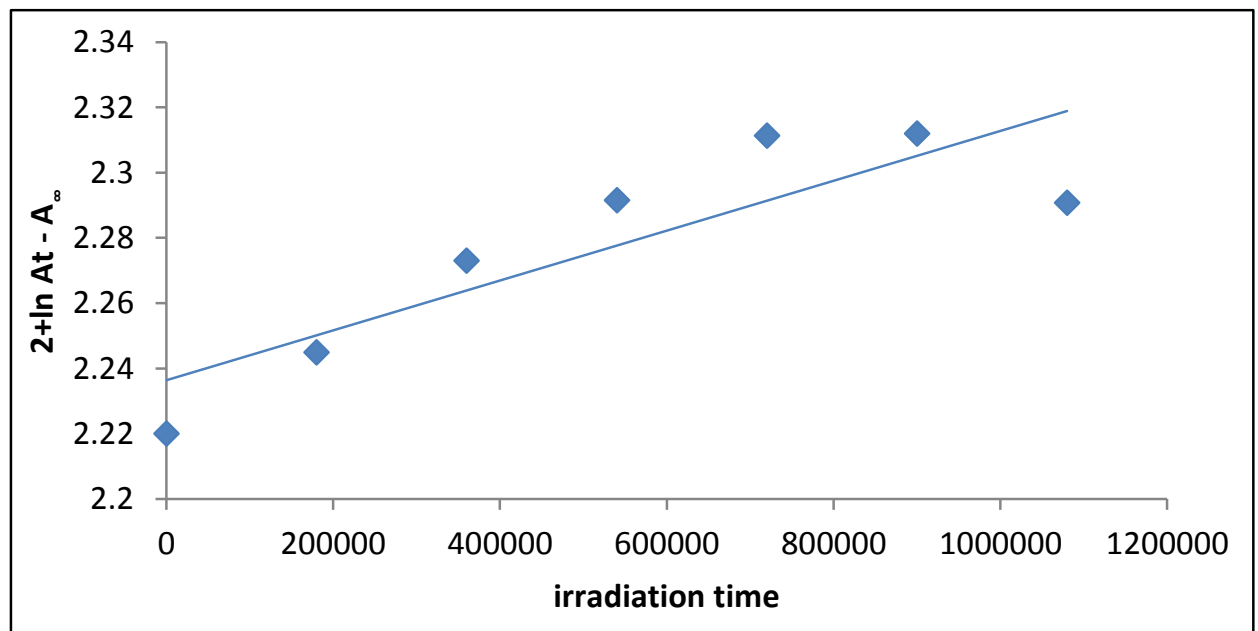

Fig.(4): plot of $\ln \left(A_{t}-A_{\infty}\right)$ vs radiation time of $P S+N i(L)_{2}$ film in thickness $50 \mu m$ at $\lambda=365 \mathrm{~nm}$. 


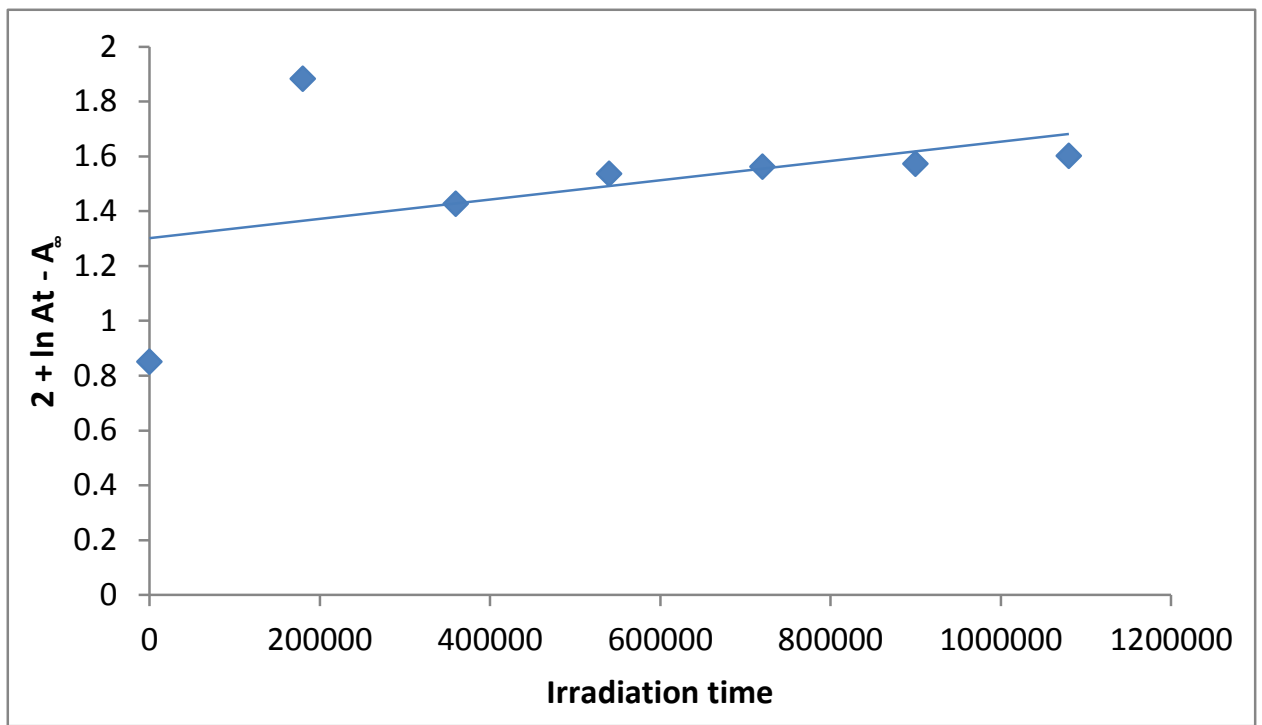

Fig.(5): plot of $\ln \left(A_{t}-A_{\infty}\right)$ vs radiation time of PS blank film in thickness $70 \mu \mathrm{m}$ at $\lambda=365 \mathrm{~nm}$.

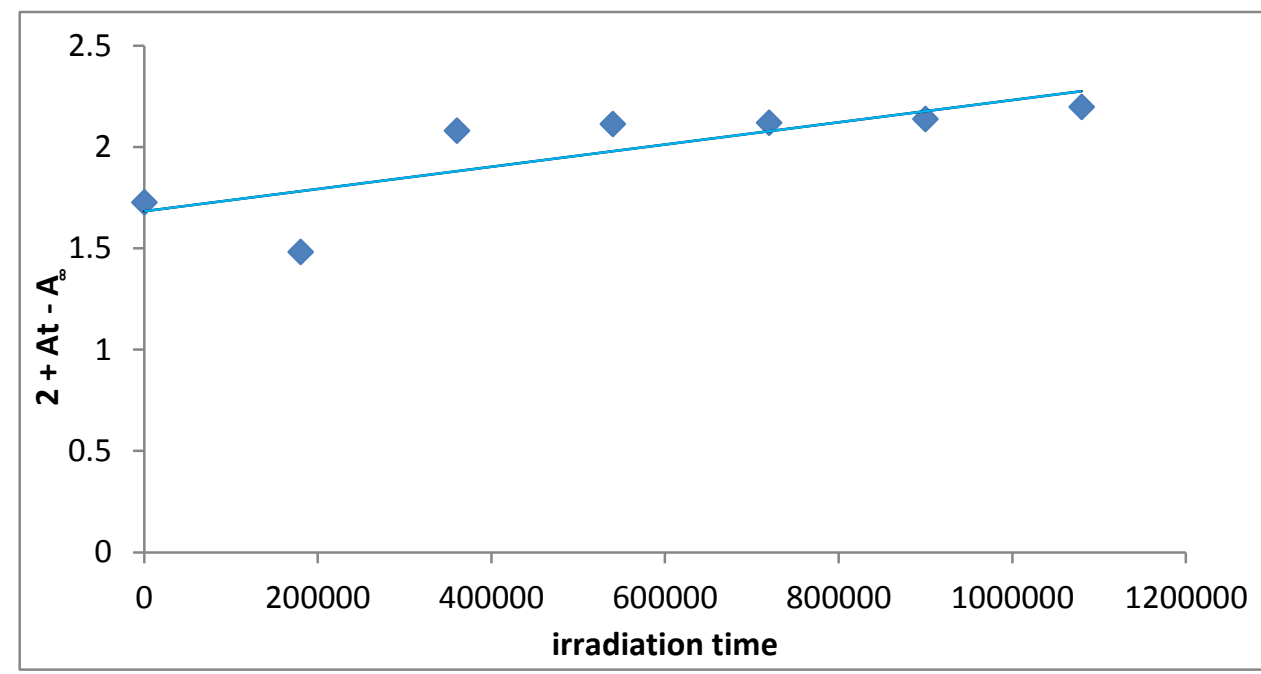

Fig.(6): plot of $\ln \left(A_{t}-A_{\infty}\right)$ vs radiation time of $P S+N i(L)_{2}$ film in thickness $70 \mu m$ at $\lambda=365 \mathrm{~nm}$.

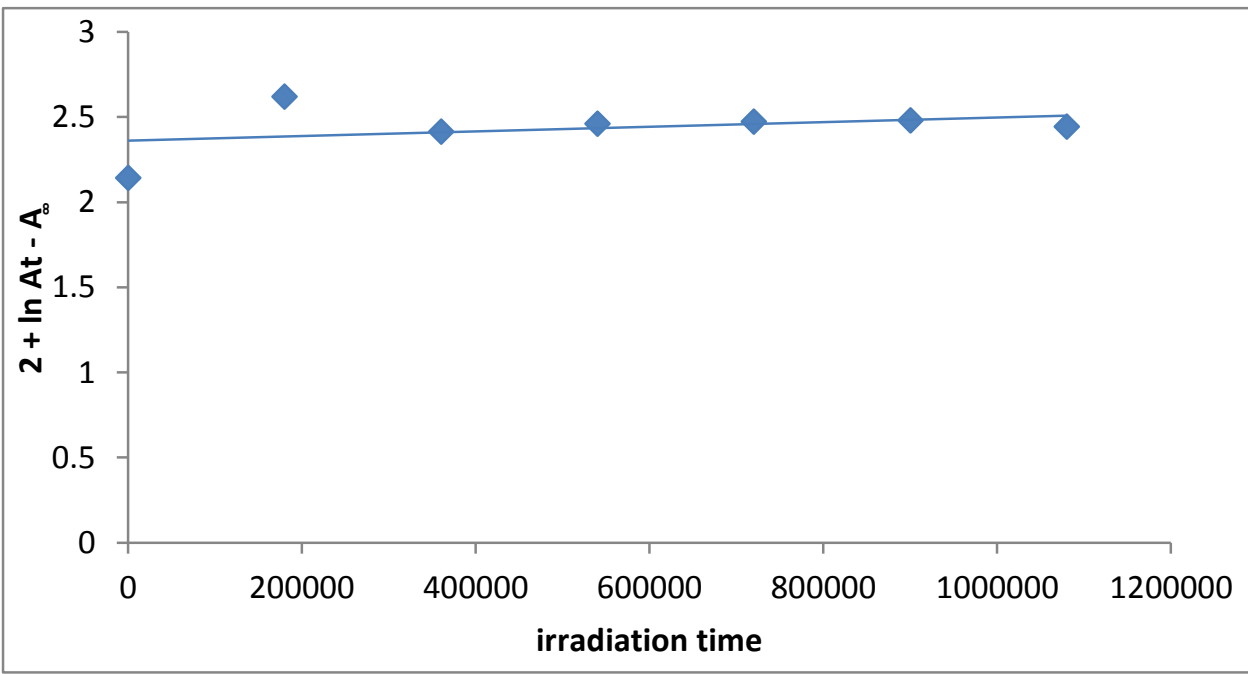

Fig. (7): plot of $\ln \left(A_{t}-A_{\infty}\right)$ vs radiation time of PS blank film in thickness $80 \mu \mathrm{m}$ at $\lambda=365 \mathrm{~nm}$. 


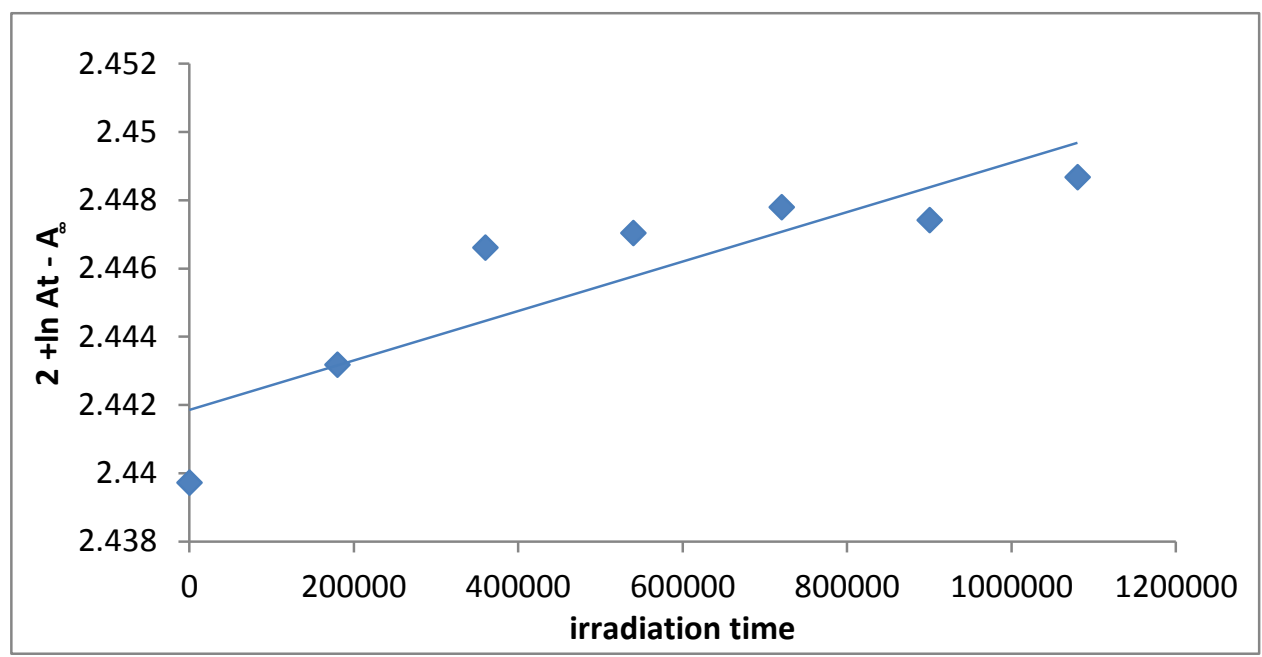

Fig. (8): plot of $\ln \left(A_{t}-A_{\infty}\right)$ vs radiation time of $P S+N i(L)_{2}$ film in thickness $90 \mu m$ at $\lambda=365 \mathrm{~nm}$.

Table (1)

The values of $k_{d}$ for PS films in different thickness comprising $(0.5 \%$ by weight) of $N i(I I)$ complex.

\begin{tabular}{|c|c|c||}
\hline \multicolumn{2}{||c|}{ PS Films with different thickness } & $\begin{array}{c}\boldsymbol{k}_{\boldsymbol{d}} \\
\left(\mathrm{sec}^{-1}\right)\end{array}$ \\
\hline \hline \multirow{2}{*}{$(50 \mu \mathrm{m})$} & PS (blank) & $5 \times 10^{-7}$ \\
& PS + Ni(L) 2 & $4 \times 10^{-7}$ \\
\hline \multirow{2}{*}{$(60 \mu \mathrm{m})$} & PS (blank) & $3 \times 10^{-7}$ \\
& PS + Ni(L) 2 & $1 \times 10^{-7}$ \\
\hline \multirow{2}{*}{$(70 \mu \mathrm{m})$} & PS (blank) & $8 \times 10^{-8}$ \\
& PS + Ni(L) 2 & $2 \times 10^{-8}$ \\
\hline \multirow{2}{*}{$(80 \mu \mathrm{m})$} & PS (blank) & $1 \times 10^{-8}$ \\
& PS + Ni(L) 2 & $9 \times 10^{-9}$ \\
\hline \multirow{2}{*}{$(90 \mu \mathrm{m})$} & PS (blank) & $8 \times 10^{-9}$ \\
& PS + Ni(L) 2 & $7 \times 10^{-9}$ \\
\hline
\end{tabular}

The consequences in Table (1) shows that the $k_{d}$ values decrease with increase the thickness of modified PS films, which mean that the stability of this modified polymers towards UV light increased with increase the thickness of films. The reason of this might be because of the point that the energy was absorbed at one position and the electronic excitation was circulated over a great number of bonds in PS polymer. Consequently therefore, the option to break a single bond becomes little or energy absorption can be dissipated by non-reactive processes.

Proposed Mechanisms of Photostabilization of PS using 4-amino-5-(pyridyl)-4H-1,2,4triazole-3-thiol Complexes

The photostabilization of PS with triazole complexes proceeds through the UV absorber, peroxide decomposer and radical scavenger mechanisms. These stabilizers cause polymer stability in the long term. Nickel chelate complexes usually recognized as photostabilizers for poly olefins by peroxide decomposer and excited state quencher, Accordingly, they are act as potohstabilizers for the PS by peroxide decomposer and excited-state quencher [36,37]. Fig.(9) displays the proposed mechanism for photostabilization of PS polymer using nickel chelate complex by way of peroxide decomposer. 

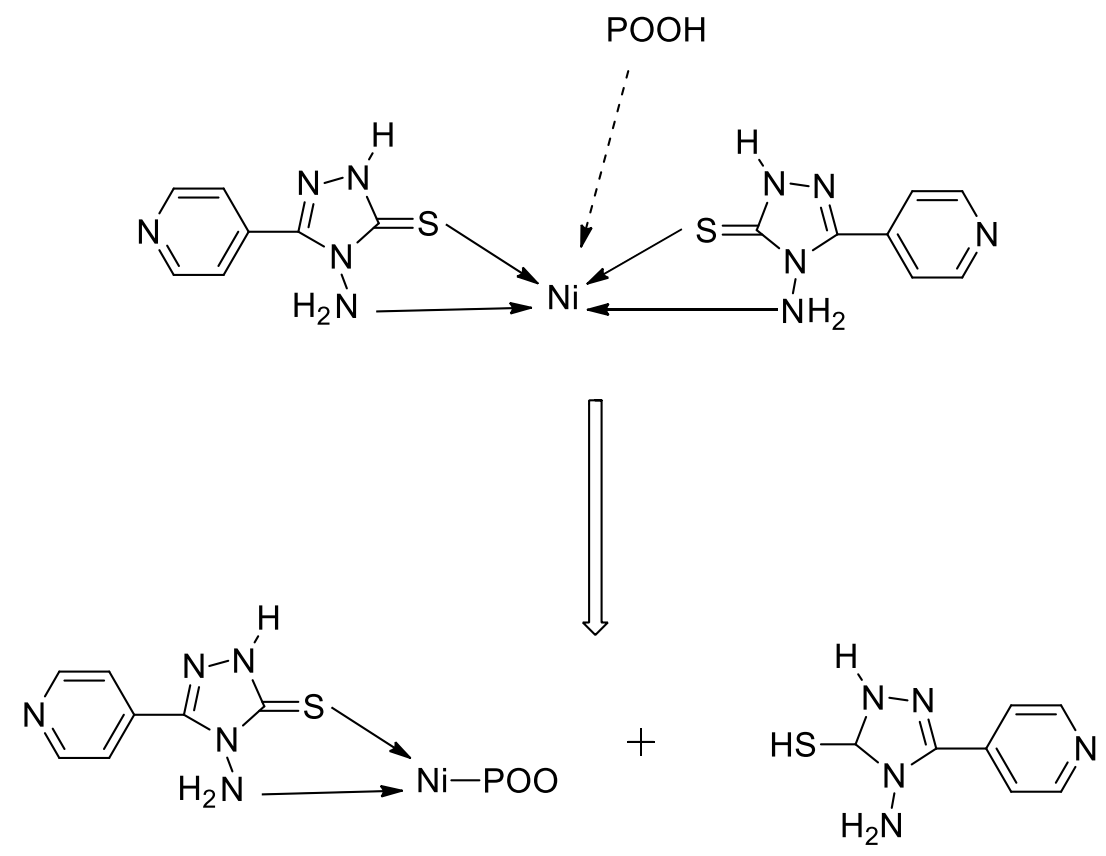

Fig. (9): Proposed mechanism of photostabilization of polystyrene utilizing Ni (II) Complex as peroxide decomposer.

This Nickel chelate complex as well functions as a radical scavenger by energy transference and creating inactive charge transference complexes between chelate of metal and the excited state of chromophores group (POO.) and stabilize by resonance structures [38] as clarify in the Fig.(10).<smiles>Nn1c(SCCN2CNNC2=S)n[nH]c1=S</smiles>

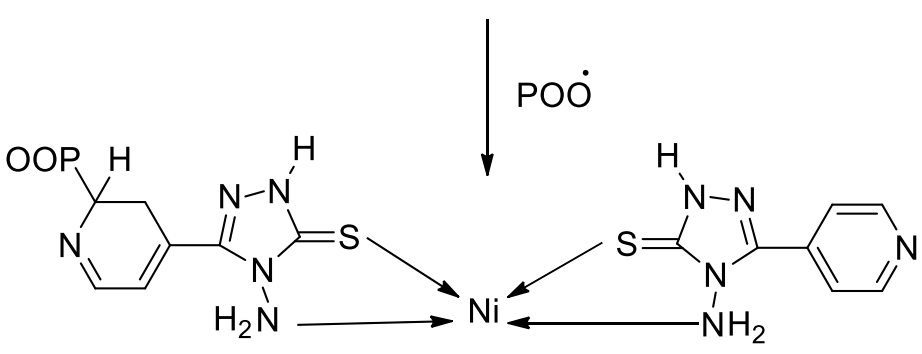

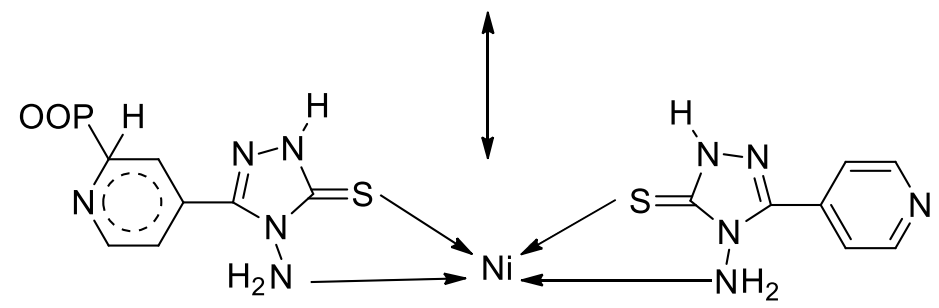

Fig. (10): Proposed mechanism for photostabilization of Polystyrene utilizing Ni(II) complex as radical scavengers. 
In the stabilizing process, the triazole ring has an influential role by acting as UV light absorber [39-42], it disperses the UV energy to inoffensive heat energy.

\section{Coniclusions}

In this paper, the photo-stabilization of polystyrene (PS) films in different thickness by using $\mathrm{Ni}$ (II) with bis(4-amino-5-(pyridyl)4H-1,2,4-triazole-3-thiol) complex have been studied. The complex that utilized in this paper was good photo-stabilizer for PS films. It stabilizes the PS films by counting mechanics such as ultraviolet absorption, radical scavenger, and peroxide decomposer.

\section{Acknowledgements}

The project was supported by Al-Nahrain University and Universiti Teknologi MARA.

\section{References}

[1] Hu X., He Q., Lu H., Chen H., Fabrication of gold microelectrodes on polystyrene sheets by UV-directed electroless plating and its application in electrochemical detection, J. Electroanaly Chem., 638, 2127, 2010.

[2] Rahman A., Ali I., Al Zahrani S., Eleithy R.H., A Review of The Applications OF Nanocarbon Polymer Composites, NANO Brief Rep. Rev., 6, 185-203, 2011.

[3] Meenakshi P., Noorjahan E., Rajini R., Venkateswarlu U., Crose S., Mechanical and microstructure studies on the modification of CA film by blending with Polystyrene, Indian Academy of Sciences, 25, 25-29. Functional, Polymer 71, 480488, 2002.

[4] Hashim H., El-Hiti G., Alotaibi M., Ahmed D., Yousif E., Fabrication of ordered honeycomb porous poly(vinyl chloride) thin film doped with a Schiff base and nickel(II) chloride, Heliyon, Elsevier Ltd 4, e00743, 1-7, 2018.

[5] Saitoh A., Amutharani D., Yamamoto Y., Tsujita Y., Yoshimizu H., Okamoto S., Structure and properties of the mesophase of syndiotactic polystyrene IV. Release of guest molecules from $\delta$ form of syndiotactic polystyrene by time resolved FT-IR and WAXD measurement, Polym J., 35(11), 868-871, 2003.
[6] Gupper A., Kazarian G., Study of solvent diffusion and solvent induced crystallization syndiotactic polystyrene using FTIR spectroscopy and imaging macromolecules, 38(6), 2327-2332, 2005.

[7] Yousif E., Salimon J., Salih N., Jawad A., Win Y., New stabilizers for PVC based on some diorganotin(IV) complexes with benzamidoleucine, Arabian Journal of Chemistry, 9, S1394-S1401, 2016.

[8] Ghazi D., El-Hiti G., Yousif E., Ahmed D., and Alotaibi M., The Effect of Ultraviolet Irradiation on the Physicochemical Properties of Poly(vinyl Chloride) Films Containing Organotin(IV) Complexes as Photostabilizers, Molecules, 23, 254, 2018.

[9] Yousif E., Abdalla M., Ahmed A., Salimon J., and Salih N., Photochemical stability and photostabilizing efficiency of poly(methyl methacrylate) based on 2-thioacetic acid-5phenyl-1,3,4-oxadiazole complexes, Arabian Journal of Chemistry, 9: S595S601, 2016.

[10] Ali M., El-Hiti G., and Yousif E., Photostabilizing Efficiency of Poly(vinyl chloride) in the Presence of Organotin(IV) Complexes as Photostabilizers, Molecules, 21(1151), 2-16, 2016.

[11] Galdi A., Foltis P., Shah A., UV protecting composition and methods of use, US patent, Application, 2010-118415, 2010.

[12] Pospisil J., Pilar J., Billingham C., Marek A., Horak Z., Nespurek S., Factors affecting accelerated testing of polymer photostability, Polymer Degradation Stabilization, 91, 417-422, 2006.

[13] Bojinov B., and Grabchev K., Novel functionalized 2-(2-hydroxyphenyl)benzotriazole-benzo[de]isoquinoline-1,3dione fluorescent UV absorbers: Synthesis and photostabilizing efficiency, Polym. Photochem. Photobiol., 172, 308-315, 2005.

[14] Rabek J. ,and Ranby B., Studied on the photooxidation mechanism of polymers, photolysis and photooxidation of polystyrene. Journal of polymer science, 12 , 273-291, 1974.

[15] Goldshtein J., Margel S., Synthesis and characterization of polystyrene/2-(5-chloro2Hbenzotriazole-2-yl)-6-(1,1dimethylethyl)-4-methyl-phenol composite 
microspheres of narrow size distribution for UV irradiation protection, Colloid Polym. Sci., 289, 1863-1874, 2011.

[16] Shih K., Chen H., Chu L., Cheng C., Chang, C., Zhu Y., and Kuo W., Photocrosslinking of pendent uracil units provides supramolecular hole injection/ transport conducting polymers for highly efficient light-emitting diodes, Polymers, 7 , 804-818, 2015.

[17] Rabie T., Khalil M., Antimicrobial agents as photostabilizers for rigid poly(vinyl chloride)., Polym Adv Technol., 23,13941402, 2012.

[18] Bella F., Griffini G., Gerosa M., Turri S., and Bongiovanni R., Performance and stability improvements for dye-sensitized solar cells in the presence of luminescent coatings, J. Power Sources, 283, 195-203, 2015.

[19] Fouassier P., and Lalevée J., Photochemical production of interpenetrating polymer networks; simultaneousi Initiation of radical and cationic polymerization reactions, Polymers, 6, 2588-2610, 2014.

[20] Mosná cek, J., Kundys A., and Andicsová A., Reversible-deactivation radical polymerization of methyl methacrylate induced by photochemical reduction of various copper catalysts, Polymers, 6, 2862-2874, 2014.

[21] Balakit, A., Ahmed A., El-Hiti G., Smith K., and Yousif E., Synthesis of new thiophene derivatives and their use as photostabilizers for rigid poly(vinyl chloride), Int. J. Polym. Sci., 2015, 10, 2015.

[22] Yousif E., El-Hiti G., Haddad, R., and Balakit A., Photochemical stability and photostabilizing efficiency of poly(methyl methacrylate) based on 2-(6methoxynaphthalen-2-yl)propanoate metal ion complexes, Polymers, 7, 1005-1019, 2015.

[23] Szarka G., Domjan A., Szakacs T., Ivan B., Oil from poly(vinyl chloride): unprecedented degradative chain scission under mild thermooxidative conditions, Polym Degrad Stab., 97, 1787-1793,2012.

[24] Smith K., Balakit A., and El-Hiti G., Poly(propylene sulfide)-borane: Convenient and versatile reagent for organic synthesis, Tetrahedron, 68, 7834-7839, 2012.

[25] Yousif E., Ahmed D.S., Ahmed A.A., Hameed A.S., Muhamed S.H., Yusop R.M., Redwan A., Mohammed S.A. The effect of high UV radiation exposure environment on the novel PVC polymers. Env. Sci. and Poll. Res. 26, 9945-9954, 2019.

[26] Shaalan N., Laftah N., El-Hiti G., Alotaibi M.,Raad Muslih, Ahmed D., and Yousif E., Poly(vinyl Chloride) Photostabilization in thePresence of Schiff Bases Containing aThiadiazole Moiety, Molecules, 23, 913, 2018.

[27] Haddad R., Yousif E. and Ahmed A., Synthesis and characterization of transition metal complexes of 4-Amino-5-pyridyl-4H1,2,4-triazole-3-thiol, Springer Plus, 2, 510516, 2013.

[28] El-Hiti G.A., Alotaibi M.H., Ahmed, A.A., Hamad, B.A., Ahmed, D.S., Ahmed A. Hashim H., Yousif E. The Morphology and Performance of Poly(Vinyl Chloride) Containing Melamine Schiff Bases against Ultraviolet Light, Molecules, 24, 803, 2019.

[29] Yousif E., Salimon J., and Salih N., New stabilizer for polystyrene based on 2Thioacetic Acid Benzothiazol complexes, J. of applied polymer Science, 125, 19221927, 2012.

[30] Yousif E., Asaad N., Ahmed D.S., Mohammed S.A., Jawad A.H., A Spectral, Optical, Microscopic Study, Synthesis and Characterization of PVC Films Containing Schiff Base Complexes. Baghdad Sci. J. 16, 2019.

[31] Zan, L., Wang S., Fa W., Hu Y., Tian L., and Deng K., Solid-Phase Photocatalytic Degradation of Polystyrene with Modified Nano- $\mathrm{TiO}_{2}$ Catalyst, j. of Polymer, 47, 8155-8162, 2006.

[32] Yousif E., El-Hiti G., Hussain Z., and Altaie A., Viscoelastic, Spectroscopic and Microscopic Study of the Photo Irradiation Effect on the Stability of PVC in the Presence of Sulfamethoxazole Schiff's Bases, Polymers, 7, 2190-2204, 2015.

[33] Hussain Z., El-Hiti G., Ahmed A., Altaee N., and Yousif E., Photocatalytic Degradation of Polyhydroxybutyrate Films Using Titanium Dioxide Nanoparticles as a 
Photocatalyst1, Russian Journal of Applied Chemistry, 89(9), 1536-1543, 2016.

[34] Shih K., Chen H., Chu L., Cheng, C.-C.; Chang C., Zhu Y., and Kuo W., Photocrosslinking of pendent uracil units provides supramolecular hole injection/ transport conducting polymers for highly efficient light-emitting diodes, Polymers, 7 , 804-818, 2015.

[35] Hussain Z., Yousif E., Altaie A and Zageer D., Study the Rate Constant of Photostabilization of PVC in Presence of Schiff's Bases of Sulphamethoxazole, Journal of Al-Nahrain university Science, 17(4), 39-43, 2014.

[36] Mosnácek, J., Kundys, A., and Andicsová, A., Reversible-deactivation radical polymerization of methyl methacrylate induced by photochemical reduction of various copper catalysts. Polymers, 6, 2862-2874, 2014.

[37] Yousif, E., Balakit, A. A., Ahmed A., ElHiti, G. A., Smith, K., Synthesis of new thiophene derivatives and their use as photostabilizers for rigid poly (vinyl chloride) Int. J. of Polym. Sci. 2015.

[38] Alotaibi, M.H., El-Hiti G.A., Yousif E., Ahmed, D.S., Hashim H., Hameed A.S., Ahmed, Evaluation of the use of polyphosphates as photostabilizers and in the formation of ball-like polystyrene materials J. of Polym. Res. 26, 161, 2019.

[39] Salman H., Yousif E., Shneine J., Ahmed A., Synthesis and Characterization on some Metal Ions of 2-(6-Methoxynaphthalen-2Yl) Propanoate Complexes, J. Al-Nahrain Uni., 16, 49-50.

[40] Yousif E., Salimon, J., and Salih, N., New photostabilizers for PVC based on some diorganotin (IV) complexes., J. Saudi Chem. Soc., 19, 133-141, 2015.

[41] Ahmed D.S., El-Hiti G.A., Hameed A.S., Yousif E., Ahmed A. New tetra-Schiff bases as efficient photostabilizers for poly(vinyl chloride), Molecules, 22, 1506, 2017.

[42] Ahmed D.S., El-Hiti G.A., Yousif E., Hameed A.S. Polyphosphates as Inhibitors for Poly(vinyl Chloride) Photodegradation. Molecules, 22, 1849, 2017.

[43] Ahmed D.S., El-Hiti G.A., Hashim H., Noaman R., Hameed A.S., Yousif E.
Physical and morphological properties of poly(vinyl chloride) films upon irradiation in the presence of tetra schiff bases as photostabilizers. Arab J. Phys. Chem., 5, 2018. 